\title{
Association studies on I I published colorectal cancer risk loci
}

\author{
S von Holst', S Picelli', D Edler', C Lenander ${ }^{2}$, J Dalén ${ }^{3}$, F Hjern ${ }^{4}, \mathbf{N}$ Lundqvist $^{5}$, U Lindforss', L Påhlman ${ }^{6}$, \\ K Smedh $^{7}$, A Törnqvist ${ }^{8}$, J Holm ${ }^{9}$, M Janson ${ }^{10}$, M Andersson ${ }^{11}$, S Ekelund ${ }^{12}$, L Olsson', S Ghazi ${ }^{13}$, \\ N Papadogiannakis ${ }^{13}$, A Tenesa ${ }^{14,15}$, SM Farrington ${ }^{14,15}$, H Campbell ${ }^{14,15,16}$, MG Dunlop ${ }^{14,15}$ and A Lindblom ${ }^{*, 1}$
}

'Department of Molecular Medicine and Surgery, Karolinska Institutet, Stockholm SI 7I 76, Sweden; ${ }^{2}$ Department of Clinical Sciences, Danderyd Hospital, Karolinska Institutet, Stockholm, Sweden; ${ }^{3}$ Department of Surgery, St Görans Hospital, Stockholm, Sweden; ${ }^{4}$ Division of Surgery, Department of Clinical Science, Karolinska Institutet at Danderyds Hospital, Stockholm, Sweden; ${ }^{5}$ Norrtälje Hospital, Norrtälje, Sweden; ${ }^{6}$ Department of Surgery, Uppsala University Hospital, Uppsala, Sweden; ${ }^{7}$ Colorectal Unit, Department of Surgery, Central Hospital, Västerås, Sweden; ${ }^{8}$ Department of Surgery, Central Hospital, Karlstad, Sweden; ${ }^{9}$ Länssjukhuset Gävle-Sandviken, Gävle, Sweden; ${ }^{10}$ Department of Clinical Science, Intervention and Techniques (CLINTEC), Karolinska Institutet, Karolinska University Hospital Huddinge, Sweden; "'Department of Surgery, Örebro University Hospital, Örebro, Sweden;

${ }^{12}$ Department of Clinical Science and Education, Södersjukhuset, Karolinska Institutet, Stockholm, Sweden; ${ }^{13}$ Division of Pathology, Department of Laboratory Medicine, Karolinska Institute, Stockholm, Sweden; ${ }^{14}$ Colon Cancer Genetics Group and Academic Coloproctology, Institute of Genetics and Molecular Medicine, University of Edinburgh, Edinburgh EH4 2XU, UK; ${ }^{15}$ MRC Human Genetics Unit, Western General Hospital, Edinburgh EH4 2XU, UK; ${ }^{16}$ Public Health Sciences, University of Edinburgh, Teviot Place, Edinburgh EH8 9AG, UK

\begin{abstract}
BACKGROUND: Recently, several genome-wide association studies (GWAS) have independently found numerous loci at which common single-nucleotide polymorphisms (SNPs) modestly influence the risk of developing colorectal cancer. The aim of this study was to test I I loci, reported to be associated with an increased or decreased risk of colorectal cancer: 8q23.3 (rs I 6892766), 8q24.2 I (rs6983267), 9p24 (rs7|9725), I0p|4 (rs|0795668), I lq23.I (rs3802842), |4q22.2 (rs4444235), I5ql3.3 (rs4779584), I6q22.I

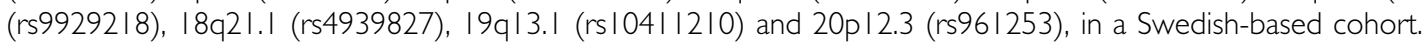

METHODS: The cohort was composed of 1786 cases and 1749 controls that were genotyped and analysed statistically. Genotypephenotype analysis, for all II SNPs and sex, age of onset, family history of CRC and tumour location, was performed.

RESULTS: Of eleven loci, 5 showed statistically significant odds ratios similar to previously published findings: 8q23.3, 8q24.2I, I0p I4,

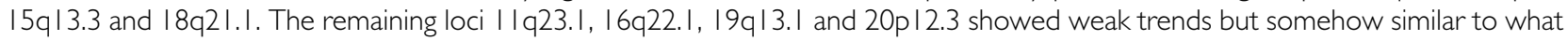
was previously published. The loci 9p24 and 14q22.2 could not be confirmed. We show a higher number of risk alleles in affected individuals compared to controls. Four statistically significant genotype-phenotype associations were found; the $G$ allele of rs6983267 was associated to older age, the G allele of rs 1075668 was associated with a younger age and sporadic cases, and the T allele of rs 1041 I 210 was associated with younger age.

CONCLUSIONS: Our study, using a Swedish population, supports most genetic variants published in GWAS. More studies are needed to validate the genotype-phenotype correlations.
\end{abstract}

British Journal of Cancer (2010) 103, 575-580. doi:10.1038/sj.bjc.6605774 www.bjcancer.com

Published online 20 July 2010

(c) 2010 Cancer Research UK

Keywords: colorectal cancer; SNP (single-nucleotide polymorphism); association study; risk predisposition

Until some years ago, the candidate-gene approach was the only method available to the researchers for identifying potentially pathogenic variants. However, the fast technological development and the consequent acquisition of large amount of data in the past decade shifted the focus of research to genome-wide association studies (GWAS). Recent GWAS have identified multiple genetic loci associated with an increased or decreased risk of colorectal cancer (CRC) on 8q23.3, 8q24.21, 9p24, 10p14, 11q23.1, 14q22.2, $15 \mathrm{q} 13.3,16 \mathrm{q} 22.1,18 \mathrm{q} 21.1,19 \mathrm{q} 13.1$ and 20p12.3, explaining, at least to some extent, the genetics behind CRC as a complex disease (Broderick et al, 2007; Haiman et al, 2007; Tomlinson et al, 2007, 2008; Zanke et al, 2007; Houlston et al, 2008; Jaeger et al, 2008; Tenesa et al, 2008). Each of these loci is associated with a modest

*Corresponding: Professor A Lindblom; E-mail: annika.lindblom@ki.se Received 17 February 2010; revised 21 May 2010; accepted II June 2010; published online 20 July 2010 risk and, although fairly common they contribute very little to the overall burden of CRC. This case-control study focused on the known CRC single-nucleotide polymorphisms (SNPs) in a Swedish-based cohort and to compare our results with previous association studies in other populations. It also tested if there were more CRC patients than controls among individuals with higher number of risk alleles as reported previously (Tomlinson et al, 2010). Genotype-phenotype associations were analysed for age of onset, sex, family history of CRC and tumour location.

\section{MATERIALS AND METHODS}

\section{Subjects}

The case cohort was composed of 1786 consecutive CRC patients of Swedish origin recruited through the Swedish Low-Risk CRC Study Group from 14 different hospitals from central Sweden 
during 2004-2006. The mean age (at diagnosis) was 68.6 years (range 28-95 years), 53\% were men and $47 \%$ were women and $22 \%$ had a family history of CRC among first- or second-degree relatives. The control cohort was composed of 1749 individuals as follows: 1319 blood donors from the general population between the age of 18 and 65 years and 430 unaffected spouses of CRC patients with the mean age of $66.3(25-92)$ years, which were cancer-free and did not have a family history of any type of cancer.

\section{Loci and SNPs}

Exploiting linkage disequilibrium between SNPs, we selected one SNP from each locus among those published. Thus we genotyped rs 16892766 on $8 \mathrm{q} 23.3$, rs6983267 on $8 \mathrm{q} 24.21$, rs719725 on 9p24, rs 10795668 on $10 \mathrm{p} 14$, rs3802842 on $11 \mathrm{q} 23.1$, rs 4444235 on $14 \mathrm{q} 22.2$, rs4779584 on 15q13.3, rs9929218 on 16q22.1, rs4939827 on $18 \mathrm{q} 21.1$, rs 10411210 on $19 \mathrm{q} 13.1$, rs 961253 on $20 \mathrm{p} 12.3$ and excluded the following from the analysis: rs355527 on 20p12.3 (tagged by rs961253) and rs7259371 on 19q13.1 (tagged by rs10411210).

\section{Genotyping}

Genomic DNA was extracted from peripheral blood by standard procedures. Six of the SNPs (rs9929218, rs719725, rs4444235, rs4779584, rs10411210 and rs961253) were genotyped using TaqMan SNP Genotyping Assay (Applied Biosystems, Foster City, CA, USA). Genotyping and first-quality check of the remaining five SNPs (rs6983267, rs16892766, rs10795668, rs4939827 and rs3802842) were performed, using a technology developed by Nanogen, at deCode Genetics, Reykjavik, Iceland (http://www.decode.com).

\section{Quality control}

Sequencing was performed using Big-Dye terminator v3.1 cycle sequencing kit (Applied Biosystems), and fragments were separated on an ABI 3730 XL capillary sequencer. Chromatograms were analysed using SeqScape v2.5 (Applied Biosystems). Primers and amplification conditions are available upon request.

\section{Genotype-phenotype analysis}

We studied sex, age of onset (early $v s$ late, $>60$ years), family history of CRC (any case of CRC among first- or second-degree relatives), location, colon $v s$ rectum and right $v s$ left (proximal and distal to the splenic flexure).

\section{Statistical analysis}

Deviations of the genotype frequencies in cases and controls from those expected under Hardy-Weinberg equilibrium were calculated by $\chi^{2}$-tests (one degree of freedom). Allelic frequencies of the SNPs in the case and control groups were compared using a $\chi^{2}$-test (allele 1 (common) $v s$ allele 2 (minor)), except for rs6983267 where the common allele is suggested to be the risk allele (Tomlinson et al, 2007). To make comparisons, we chose to present risk and common allele according to previous publications. Analyses were also performed under various types of genetic models including the comparison of homozygotes (genotype $11 v s 22)$, the dominant $(11$ vs $(12+22))$, the recessive $((11+12)$ vs 22$)$ models and the allele frequency difference ((1) vs (2)). In addition, Armitage's trend test, which takes into account the individuals' genotypes rather than just alleles, (Sasieni, 1997) was performed using the DeFinetti programme provided as an online source (http://ihg2.helmholtz-muenchen.de/cgi-bin/hw/hwa1.pl). The significance level for statistical tests was set at 0.05 . Odds ratios (ORs), their 95\% confidence intervals (CIs) and their corresponding $P$-values were calculated using the same programme. The analyses were validated using Statistica 7.0 (StatSoft Inc., Tulsa, OK, USA).
Statistical analysis for the clinical parameters was carried out with Statistica, using cross-tabulation analysis. Pearson $\chi^{2}$-test was used to calculate the $P$-value, and the level of significance was set at 0.05 .

\section{RESULTS}

Genotype frequencies of cases and controls as well as ORs and $P$-values for the different analyses are shown in Table 1 . Significant associations between 5 of the 11 genotyped SNPs (rs16892766, rs6983267, rs10795668, rs4779584 and rs4939827) and CRC risk were confirmed and showed similar ORs as in previous publications (Broderick et al, 2007; Tomlinson et al, 2007, 2008; Jaeger et al, 2008). For SNP rs16892766 on 8q23.3, an increased risk of CRC was identified $(P<0.002$ for all analyses except the recessive model) with the highest OR equal to $1.34(1.13-1.60)$ for the heterozygous. Likewise, the increased risk suggested for the variant rs6983267 on 8q24.21 was confirmed in all the analyses, with the highest OR equal to $1.37(1.13-1.67)$ for the homozygous state. rs 4779584 on $15 \mathrm{q} 13.3$ has been associated with an increased risk that could be confirmed for the heterozygous individuals, $\mathrm{OR}=1.18$ (1.02-1.36). The protected effects suggested for rs10795668 on 10 p14 and rs4939827 on 18q21.1 were both confirmed for homozygous and heterozygous with an OR equal to $0.66(0.52-0.83)$ and OR $0.82(0.70-0.96)$, respectively. The ORs for rs3802842 on 11q23.1 showed a trend with an OR equal to 1.27 (NS) for homozygous. The rs9929218 on $16 q 22.1$, rs 10411210 on $19 q 13.1$ and rs961253 on 20p12.3 showed weak trends in the same direction as published (NS), whereas the two SNPs rs719725 on 9p24 and rs4444235 on $14 \mathrm{q} 22.2$ were not confirmed. The distribution of risk alleles between cases and controls in the Swedish population is shown in Figure 1. There is a clear shift with a higher number of alleles in affected individuals compared to controls.

Genotype-phenotype analysis was performed for all 11 loci and for sex, age, family history and tumour location, and the $P$-values for all analyses are shown in Table 2. Four associations were found, three for age and one for family history (Table 3). Being homozygous for the risk allele $\mathrm{G}$ for rs6983267 showed association to older age $(P=0.0014)$. In contrast, for rs 1075668 the risk allele $\mathrm{G}$ was associated with younger age $(P=0.035)$ and sporadic cases $(P=0.047)$. The $\mathrm{T}$ allele of rs10411210 was associated with younger age $(P=0.045)$ in homozygotes (Table 3$)$.

\section{DISCUSSION}

We studied SNPs on 11 loci published to be associated with an increased or decreased risk for CRC and were able to show statistically significant results for 5 of them. The first SNP, rs6983267 on 8q24.21, was published by Tomlinson et al (2007), where the most common allele $G$ was suggested to be the risk allele. Our study showed similar results as previous studies in other populations (Berndt et al, 2008; Tuupanen et al, 2008; Wokolorczyk et al, 2008; Curtin et al, 2009; Middeldorp et al, 2009). Likewise, the SNP rs 16892766 on 8 q 23.3 was similar to both the GWAS study and one replicative study (Tomlinson et al, 2008; Wijnen et al, 2009). The protective effect associated with rs10795668 on 10p14 was confirmed for homozygous carriers in the Swedish material (Tomlinson et al, 2008). The SNP rs4779584 on 15q13.3, published by Jaeger et al (2008) as a risk association with CRC was confirmed by us. For the SNP rs4939827 on 18q21.1, Broderick et al published the variant to be protective, which could also be shown by us and one previous study (Curtin et al, 2009). The SNP rs3802842 on 11q23.1 was first published by Tenesa and co-workers and confirmed by others (Pittman et al, 2008; Middeldorp et al, 2009; Wijnen et al, 2009). Our results were similar, but not statistically significant. This discrepancy could be due to different populations, sample size or study design. Wijnen et al (2009) used a Dutch population, and used mismatch repair 
Table I OR for case-control study of II published CRC susceptibility loci

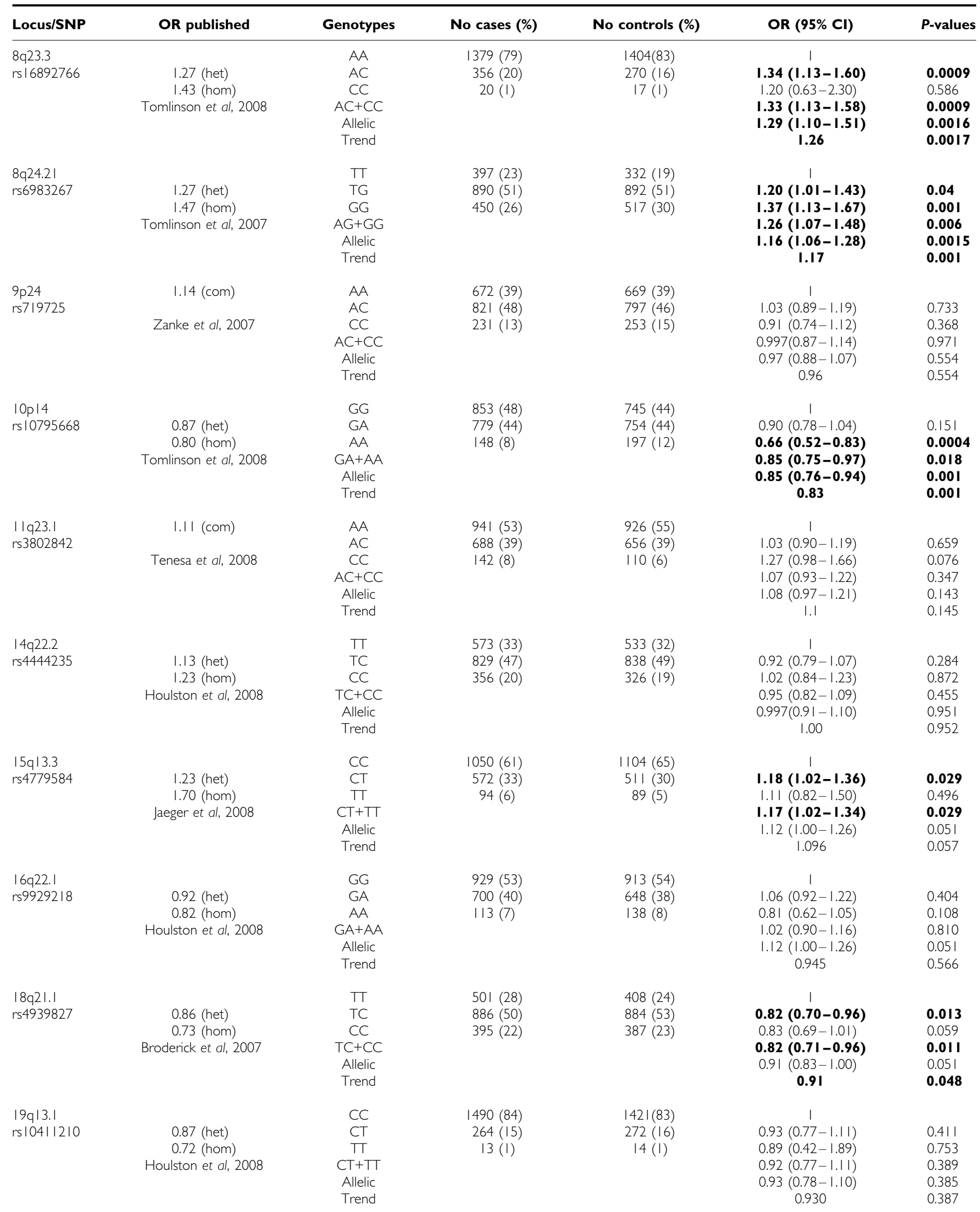


Table I (Continued)

\begin{tabular}{|c|c|c|c|c|c|c|}
\hline Locus/SNP & OR published & Genotypes & No cases (\%) & No controls (\%) & OR (95\% Cl) & $P$-values \\
\hline $20 p \mid 2.3$ & & $\mathrm{CC}$ & $694(39)$ & $693(40)$ & I & \\
\hline \multirow[t]{5}{*}{ rs961253 } & I.14 (het) & CA & $806(46)$ & 791 (46) & $1.02(0.88-1.18)$ & 0.813 \\
\hline & I.24 (hom) & $\mathrm{AA}$ & $265(15)$ & $237(14)$ & $1.12(0.9 \mid-1.37)$ & 0.290 \\
\hline & Houlston et al, 2008 & $\mathrm{CA}+\mathrm{AA}$ & & & $1.04(0.9 \mid-1.19)$ & 0.568 \\
\hline & & Allelic & & & $1.05(0.95-1.16)$ & 0.344 \\
\hline & & Trend & & & 1.05 & 0.349 \\
\hline
\end{tabular}

Abbreviations: allelic = allele frequency difference; trend = Armitage's trend test; com = common odds ratio; hom = homozygous; het = heterozygous; all = allelic. Minor allele frequencies Swedish cohort cases/controls: 8q23.3 (0.1 I/0.09), 8q24.2I (0.49/0.45), 9p24 (0.37/0.38), I0p |4 (0.30/0.34), I Iq23.I (0.27/0.26), |4q22.2 (0.44/0.44), I5q |3.3 (0.22/0.20), I6q22.I (0.27/0.27), I8q2I.I (0.47/0.49), I9q I3.I (0.08/0.09), 20p I $2.3(0.38 / 0.37)$. The bold values indicate $P<0.05$.

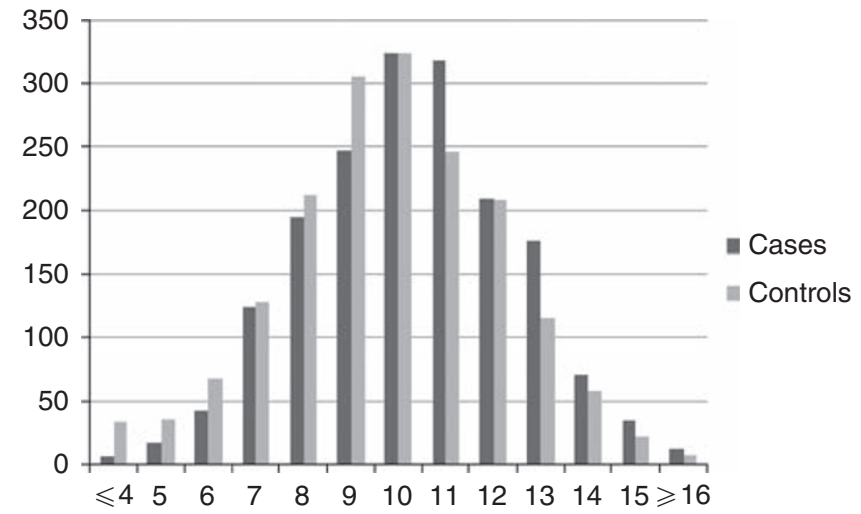

Figure I Polygenic model of I I CRC-related SNPs. Distribution of risk alleles among cases and controls: black, cases; grey, controls.

gene carriers only and no controls. The majority of the Dutch samples (995 cases and 1340 controls) used by Middeldorp et al (2009) were familial cases and Pittman et al (2008) used eight independent case - control series (10638 cases and 10457 controls) and were able to confirm significant values for most of the populations.

No association was detected for rs719725 on 9p24, initially reported in cohorts from Canada, the United States, Newfoundland, Scotland and France, which the authors themselves were unable to replicate in a second French cohort (Zanke et al, 2007). Later it was confirmed in cohorts from the American, Canadian and Australian populations (Poynter et al, 2007). Even though the distribution of the three genotypes was the same, we hypothesise that this negative result could be due to its population specificity and the causal SNP being on different haplotypes or were these results false positives. A study using British and American cohorts was also unable to detect any association for this SNP (Curtin et al, 2009).

To our knowledge, none of the remaining four SNPs has been studied in other populations yet. In fact, the confirmed five loci were the first ones to be published whereas the SNPs on 14q22.2, $16 \mathrm{q} 22.1,19 \mathrm{q} 13.1$ and $20 \mathrm{p} 12.3$ were only captured by meta-analysis of large GWAS (Houlston et al, 2008), suggesting that these four could be more difficult to replicate in follow-up studies. The three SNPs on 16q22.1, 19q13.1 and 20p12.3 did not show statistically significant values in our study. However, when looking at the ORs in the Swedish samples, association was suggested but with a wider CI compared to the first report (Houlston et al, 2008). Finally, we were unable to confirm association to CRC risk for rs4444235 on $14 \mathrm{q} 22.2$ (Houlston et al, 2008), which again could be due to a smaller size or possibly a population difference.

Another possible explanation for the different results could depend on different genotype frequencies among populations or methods used for genotyping. For all SNPs the genotype frequencies in Swedish samples were similar to published data. Regarding methods, SNP arrays were used for the GWAS, whereas other studies used Sequenom's iPLEX Gold (San Diego, CA, USA), genomic sequencing, SNPlex, PCR KASPar or TaqMan. This does not immediately explain the different results in the Swedish material. Because four of the five SNPs genotyped by DeCode and rs4778495 genotyped in Edinburgh using TaqMan were confirmed, while none of the five (rs9929218, rs719725, rs4444235, rs10411210 and rs961253) carried out in our lab showed statistically significant results we validated the results from our TaqMan analysis. In total 1000 cases and 1000 controls were sequenced for the five SNPs. The concordance was $99.8 \%$, why we do not think that the method explains the difference between our study results and previous publications.

Carrying one risk variant alone is neither necessary nor sufficient for developing CRC. However, in Figure 1 we show support for the general idea that the CRC patients carry more risk alleles compared to controls. For both cases and controls, the distribution is outlined in the diagram of carriers with a shift toward higher numbers of risk alleles in affected individuals, in line with what has been published (Tomlinson et al, 2010). Even though we did not confirm all SNPs, and used 11 SNPs instead of 10, the distribution of risk alleles showed very similar data (Figure 1) to what was published that further strengthens the results and confirms the genetic contribution by the alleles overall (Tomlinson et al, 2010).

The genotype-phenotype analysis interestingly showed four associations for three SNPs. Other studies have published genotype-phenotype analysis for only one of the loci, 8q24.21, and sex, tumour site, age at diagnosis and family history (Haiman et al, 2007; Poynter et al, 2007; Tuupanen et al, 2008). We report an association to age for rs6983267 on 8q24.21; the risk allele $\mathrm{G}$ was associated to our older patients $(P=0.0014)$. This was not seen in any of the other studies (Haiman et al, 2007; Poynter et al, 2007; Tuupanen et al, 2008), perhaps because of the different age groups used. In contrast to our study and the two other studies, Tuupanen et al (2008) for the same SNP reported an association to family history. This is not likely to depend on the definition of family history, because only our study used a different classification from the other three. In line with our results, no one found any support for sex or tumour site (Haiman et al, 2007; Poynter et al, 2007; Tuupanen et al, 2008). For rs10795668 on 10p14, we showed association to age and family history. Being homozygous for the risk alleles was associated to younger patients $(P=0.035)$ and to sporadic cases $(P=0.047)$. For rs 10411210 an association was identified for being homozygous for the risk allele in younger patients $(P=0.045)$. Replications of these genotype-phenotype analyses are needed before any conclusion can be made.

The genetic contribution to CRC as a whole has been estimated to be as high as $35 \%$ (Lichtenstein et al, 2000). Although very common in the general population, considering an additive model of inheritance the 10 SNPs discovered so far (9p24 excluded) account jointly for only about $6 \%$ of the excess genetic risk (Houlston et al, 2008). These statements leave the majority of the genetic contribution to CRC development still unexplained and 
Table 2 P-values from genotype-phenotype analysis of I I CRC susceptibility loci

\begin{tabular}{|c|c|c|c|c|c|c|c|c|c|c|c|}
\hline $\begin{array}{l}\text { SNP/loci } \\
\text { Phenotype }\end{array}$ & $\begin{array}{c}\text { rsI6892766 } \\
8 q 23.3\end{array}$ & $\begin{array}{c}\text { rs6983267 } \\
8 q 24.21\end{array}$ & $\begin{array}{c}\text { rs719725 } \\
9 p 24\end{array}$ & $\begin{array}{c}\text { rsI0795668 } \\
\text { IOpI4 }\end{array}$ & $\begin{array}{c}\text { rs3802842 } \\
\text { I lq23.I }\end{array}$ & $\begin{array}{c}\text { rs4444235 } \\
\text { I 4q22.2 }\end{array}$ & $\begin{array}{c}\text { rs4779584 } \\
|5 q| 3.3\end{array}$ & $\begin{array}{c}\text { rs9929218 } \\
16 q 22.1\end{array}$ & $\begin{array}{c}\text { rs4939827 } \\
\text { |8q2।.I }\end{array}$ & $\begin{array}{c}\text { rsI04II210 } \\
19 q 13.1\end{array}$ & $\begin{array}{c}\text { rs96 | } 253 \\
20 p \mid 2.3\end{array}$ \\
\hline Age of onset & $P=0.277$ & $P=0.0014$ & $P=0.414$ & $P=0.035$ & $P=0.683$ & $P=0.070$ & $P=0.782$ & $P=0.055$ & $P=0.606$ & $P=0.045$ & $P=0.853$ \\
\hline Sex & $P=0.251$ & $P=0.190$ & $P=0.547$ & $P=0.313$ & $P=0.892$ & $P=0.880$ & $P=0.688$ & $P=0.784$ & $P=0.569$ & $P=0.069$ & $P=0.561$ \\
\hline Family history & $P=0.998$ & $P=0.131$ & $P=0.474$ & $P=0.046$ & $P=0.607$ & $P=0.587$ & $P=0.861$ & $P=0.459$ & $P=0.131$ & $P=0.071$ & $P=0.489$ \\
\hline Rectum/colon & $P=1.000$ & $P=0.789$ & $P=0.705$ & $P=0.170$ & $P=0.787$ & $P=0.407$ & $P=0.229$ & $P=0.184$ & $P=0.472$ & $P=0.632$ & $P=0.159$ \\
\hline Location left/right & $P=0.469$ & $P=0.277$ & $P=0.240$ & $P=0.246$ & $P=0.962$ & $P=0.347$ & $P=0.309$ & $P=0.709$ & $P=0.314$ & $P=0.505$ & $P=0.985$ \\
\hline
\end{tabular}

Genotype-phenotype analysis. The bold values indicate $P<0.05$.

Table 3 Genotype-phenotype analysis for the four analysis with statistically significant results

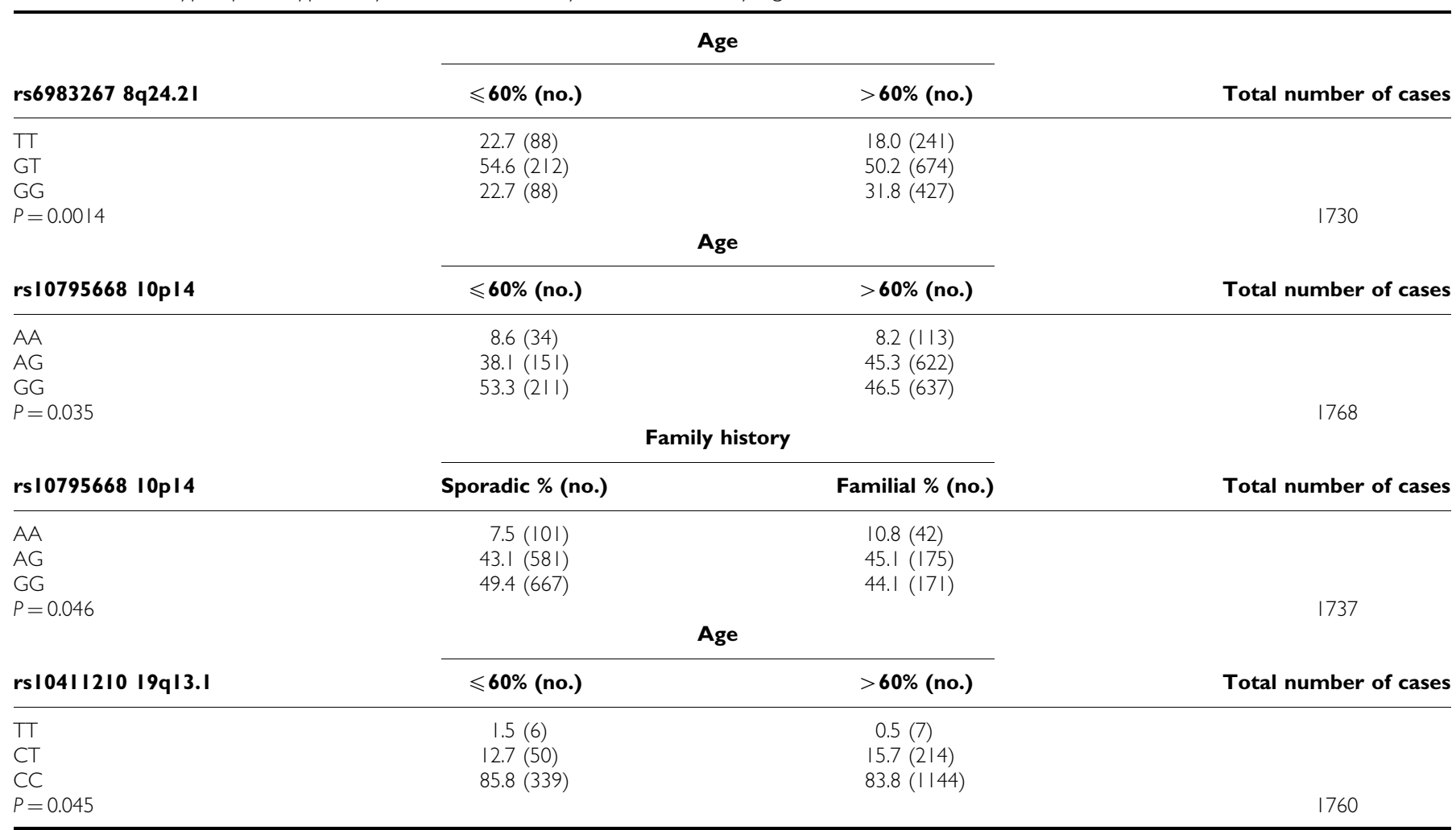

more studies aiming to define additional SNPs and hopefully also some more high-penetrant predisposing genes are welcomed.

\section{ACKNOWLEDGEMENTS}

We thank the patients for collaboration and Berith Wejderot for excellent administrative service. This study was funded by The
Swedish Cancer Society, the Swedish Research Council, Stockholm County Council and the Stockholm Cancer Society. The work carried out in Edinburgh was funded by grants from Cancer Research UK (C348/A8896); a Centre Grant from CORE as part of the Digestive Cancer Campaign (http://www.corecharity.org.uk); Scottish Government Chief Scientist Office (K/OPR/2/2/D333); Medical Research Council (G0000657-53203).

\section{REFERENCES}

Berndt SI, Potter JD, Hazra A, Yeager M, Thomas G, Makar KW, Welch R, Cross AJ, Huang WY, Schoen RE, Giovannucci E, Chan AT, Chanock SJ, Peters U, Hunter DJ, Hayes RB (2008) Pooled analysis of genetic variation at chromosome 8q24 and colorectal neoplasia risk. Hum Mol Genet 17: 2665-2672

Broderick P, Carvajal-Carmona L, Pittman AM, Webb E, Howarth K, Rowan A, Lubbe S, Spain S, Sullivan K, Fielding S, Jaeger E, Vijayakrishnan J, Kemp Z, Gorman M, Chandler I, Papaemmanuil E, Penegar S, Wood W, Sellick G, Qureshi M, Teixeira A, Domingo E, Barclay E, Martin L, Sieber O, Kerr D, Gray R, Peto J, Cazier JB,
Tomlinson I, Houlston RS (2007) A genome-wide association study shows that common alleles of SMAD7 influence colorectal cancer risk. Nat Genet 39: 1315-1317

Curtin K, Lin WY, George R, Katory M, Shorto J, Cannon-Albright LA, Bishop DT, Cox A, Camp NJ (2009) Meta association of colorectal cancer confirms risk alleles at $8 \mathrm{q} 24$ and $18 \mathrm{q} 21$. Cancer Epidemiol Biomarkers Prev 18: 616-621

Haiman CA, Le Marchand L, Yamamato J, Stram DO, Sheng X, Kolonel LN, Wu AH, Reich D, Henderson BE (2007) A common genetic risk factor for colorectal and prostate cancer. Nat Genet 39: 954-956 
Houlston RS, Webb E, Broderick P, Pittman AM, Di Bernardo MC, Lubbe S, Chandler I, Vijayakrishnan J, Sullivan K, Penegar S, Carvajal-Carmona L, Howarth K, Jaeger E, Spain SL, Walther A, Barclay E, Martin L, Gorman M, Domingo E, Teixeira AS, Kerr D, Cazier JB, Niittymaki I, Tuupanen S, Karhu A, Aaltonen LA, Tomlinson IP, Farrington SM, Tenesa A, Prendergast JG, Barnetson RA, Cetnarskyj R, Porteous ME, Pharoah PD, Koessler T, Hampe J, Buch S, Schafmayer C, Tepel J, Schreiber S, Volzke H, Chang-Claude J, Hoffmeister M, Brenner H, Zanke BW, Montpetit A, Hudson TJ, Gallinger S, Campbell H, Dunlop MG (2008) Meta-analysis of genome-wide association data identifies four new susceptibility loci for colorectal cancer. Nat Genet 40: $1426-1435$

Jaeger E, Webb E, Howarth K, Carvajal-Carmona L, Rowan A, Broderick P, Walther A, Spain S, Pittman A, Kemp Z, Sullivan K, Heinimann K, Lubbe S, Domingo E, Barclay E, Martin L, Gorman M, Chandler I, Vijayakrishnan J, Wood W, Papaemmanuil E, Penegar S, Qureshi M, Farrington S, Tenesa A, Cazier JB, Kerr D, Gray R, Peto J, Dunlop M, Campbell H, Thomas H, Houlston R, Tomlinson I (2008) Common genetic variants at the CRAC1 (HMPS) locus on chromosome 15q13.3 influence colorectal cancer risk. Nat Genet 40: 26-28

Lichtenstein P, Holm NV, Verkasalo PK, Iliadou A, Kaprio J, Koskenvuo M, Pukkala E, Skytthe A, Hemminki K (2000) Environmental and heritable factors in the causation of cancer - analyses of cohorts of twins from Sweden, Denmark, and Finland. $N$ Engl J Med 343: 78-85

Middeldorp A, Jagmohan-Changur S, van Eijk R, Tops C, Devilee P, Vasen HF, Hes FJ, Houlston R, Tomlinson I, Houwing-Duistermaat JJ, Wijnen JT, Morreau H, van Wezel T (2009) Enrichment of low penetrance susceptibility loci in a Dutch familial colorectal cancer cohort. Cancer Epidemiol Biomarkers Prev 18: 3062 - 3067

Pittman AM, Webb E, Carvajal-Carmona L, Howarth K, Di Bernardo MC, Broderick P, Spain S, Walther A, Price A, Sullivan K, Twiss P, Fielding S, Rowan A, Jaeger E, Vijayakrishnan J, Chandler I, Penegar S, Qureshi M, Lubbe S, Domingo E, Kemp Z, Barclay E, Wood W, Martin L, Gorman M, Thomas H, Peto J, Bishop T, Gray R, Maher ER, Lucassen A, Kerr D, Evans GR, van Wezel T, Morreau H, Wijnen JT, Hopper JL, Southey MC, Giles GG, Severi G, Castellvi-Bel S, Ruiz-Ponte C, Carracedo A, Castells A, Forsti A, Hemminki K, Vodicka P, Naccarati A, Lipton L, Ho JW, Cheng KK, Sham PC, Luk J, Agundez JA, Ladero JM, de la Hoya M, Caldes T, Niittymaki I, Tuupanen S, Karhu A, Aaltonen LA, Cazier JB, Tomlinson IP, Houlston RS (2008) Refinement of the basis and impact of common $11 \mathrm{q} 23.1$ variation to the risk of developing colorectal cancer. $\mathrm{Hum} \mathrm{Mol}$ Genet 17: $3720-3727$

Poynter JN, Figueiredo JC, Conti DV, Kennedy K, Gallinger S, Siegmund KD, Casey G, Thibodeau SN, Jenkins MA, Hopper JL, Byrnes GB, Baron JA, Goode EL, Tiirikainen M, Lindor N, Grove J, Newcomb P, Jass J, Young J, Potter JD, Haile RW, Duggan DJ, Le Marchand L (2007) Variants on 9p24 and 8q24 are associated with risk of colorectal cancer: results from the Colon Cancer Family Registry. Cancer Res 67: $11128-11132$

Sasieni PD (1997) From genotypes to genes: doubling the sample size. Biometrics 53: $1253-1261$

Tenesa A, Farrington SM, Prendergast JG, Porteous ME, Walker M, Haq N, Barnetson RA, Theodoratou E, Cetnarskyj R, Cartwright N, Semple C, Clark AJ, Reid FJ, Smith LA, Kavoussanakis K, Koessler T, Pharoah PD, Buch S, Schafmayer C, Tepel J, Schreiber S, Volzke H, Schmidt CO, Hampe J, Chang-Claude J, Hoffmeister M, Brenner H, Wilkening S, Canzian F, Capella G, Moreno V, Deary IJ, Starr JM, Tomlinson IP, Kemp Z, Howarth K, Carvajal-Carmona L, Webb E, Broderick P, Vijayakrishnan J, Houlston RS, Rennert G, Ballinger D, Rozek L, Gruber SB, Matsuda K, Kidokoro T, Nakamura Y, Zanke BW, Greenwood CM, Rangrej J, Kustra R, Montpetit A, Hudson TJ, Gallinger S, Campbell H, Dunlop MG (2008) Genome-wide association scan identifies a colorectal cancer susceptibility locus on 11q23 and replicates risk loci at $8 \mathrm{q} 24$ and 18q21. Nat Genet 40: 631-637

Tomlinson I, Webb E, Carvajal-Carmona L, Broderick P, Kemp Z, Spain S, Penegar S, Chandler I, Gorman M, Wood W, Barclay E, Lubbe S, Martin L, Sellick G, Jaeger E, Hubner R, Wild R, Rowan A, Fielding S, Howarth K, Silver A, Atkin W, Muir K, Logan R, Kerr D, Johnstone E, Sieber O, Gray R, Thomas H, Peto J, Cazier JB, Houlston R (2007) A genome-wide association scan of tag SNPs identifies a susceptibility variant for colorectal cancer at 8q24.21. Nat Genet 39: 984-988

Tomlinson IP, Dunlop M, Campbell H, Zanke B, Gallinger S, Hudson T, Koessler T, Pharoah PD, Niittymakix I, Tuupanenx S, Aaltonen LA, Hemminki K, Lindblom A, Forsti A, Sieber O, Lipton L, van Wezel T, Morreau H, Wijnen JT, Devilee P, Matsuda K, Nakamura Y, Castellvi-Bel S, Ruiz-Ponte C, Castells A, Carracedo A, Ho JW, Sham P, Hofstra RM, Vodicka P, Brenner H, Hampe J, Schafmayer C, Tepel J, Schreiber S, Volzke H, Lerch MM, Schmidt CA, Buch S, Moreno V, Villanueva CM, Peterlongo P, Radice P, Echeverry MM, Velez A, Carvajal-Carmona L, Scott R, Penegar S, Broderick P, Tenesa A, Houlston RS (2010) COGENT (COlorectal cancer GENeTics): an international consortium to study the role of polymorphic variation on the risk of colorectal cancer. Br J Cancer 102(2): 447-454

Tomlinson IP, Webb E, Carvajal-Carmona L, Broderick P, Howarth K, Pittman AM, Spain S, Lubbe S, Walther A, Sullivan K, Jaeger E, Fielding S, Rowan A, Vijayakrishnan J, Domingo E, Chandler I, Kemp Z, Quresh M, Farrington SM, Tenesa A, Prendergast JG, Barnetson RA, Penegar S, Barclay E, Wood W, Martin L, Gorman M, Thomas H, Peto J, Bishop DT, Gray R, Maher ER, Lucassen A, Kerr D, Evans DG, Schafmayer C, Buch S, Volzke H, Hampe J, Schreiber S, John U, Koessler T, Pharoah P, van Wezel T, Morreau H, Wijnen JT, Hopper JL, Southey MC, Giles GG, Severi G, Castellvi-Bel S, Ruiz-Ponte C, Carracedo A, Castells A, Forsti A, Hemminki K, Vodicka P, Naccarati A, Lipton L, Ho JW, Cheng KK, Sham PC, Luk J, Agundez JA, Ladero JM, de la Hoya M, Caldes T, Niittymaki I, Tuupanen S, Karhu A, Aaltonen L, Cazier JB, Campbell H, Dunlop MG Houlston RS (2008) A genome-wide association study identifies colorectal cancer susceptibility loci on chromosomes 10p14 and 8q23.3. Nat Genet 40: 623-630

Tuupanen S, Niittymaki I, Nousiainen K, Vanharanta S, Mecklin JP, Nuorva K, Jarvinen H, Hautaniemi S, Karhu A, Aaltonen LA (2008) Allelic imbalance at rs6983267 suggests selection of the risk allele in somatic colorectal tumor evolution. Cancer Res 68: 14-17

Wijnen JT, Brohet RM, van Eijk R, Jagmohan-Changur S, Middeldorp A, Tops CM, van Puijenbroek M, Ausems MG, Gomez Garcia E, Hes FJ, Hoogerbrugge N, Menko FH, van Os TA, Sijmons RH, Verhoef S, Wagner A, Nagengast FM, Kleibeuker JH, Devilee P, Morreau H, Goldgar D, Tomlinson IP, Houlston RS, van Wezel T, Vasen HF (2009) Chromosome $8 \mathrm{q} 23.3$ and 11q23.1 variants modify colorectal cancer risk in Lynch syndrome. Gastroenterology 136: $131-137$

Wokolorczyk D, Gliniewicz B, Sikorski A, Zlowocka E, Masojc B, Debniak T, Matyjasik J, Mierzejewski M, Medrek K, Oszutowska D, Suchy J, Gronwald J, Teodorczyk U, Huzarski T, Byrski T, Jakubowska A, Gorski B, van de Wetering T, Walczak S, Narod SA, Lubinski J, Cybulski C (2008) A range of cancers is associated with the rs6983267 marker on chromosome 8. Cancer Res 68: $9982-9986$

Zanke BW, Greenwood CM, Rangrej J, Kustra R, Tenesa A, Farrington SM, Prendergast J, Olschwang S, Chiang T, Crowdy E, Ferretti V, Laflamme P, Sundararajan S, Roumy S, Olivier JF, Robidoux F, Sladek R, Montpetit A, Campbell P, Bezieau S, O'Shea AM, Zogopoulos G, Cotterchio M, Newcomb P, McLaughlin J, Younghusband B, Green R, Green J, Porteous ME, Campbell H, Blanche H, Sahbatou M, Tubacher E, Bonaiti-Pellie C, Buecher B, Riboli E, Kury S, Chanock SJ, Potter J, Thomas G, Gallinger S, Hudson TJ, Dunlop MG (2007) Genome-wide association scan identifies a colorectal cancer susceptibility locus on chromosome 8q24. Nat Genet 39: $989-994$ 